\title{
BURKITT LYMPHOMA AS A CAUSE OF RECURRENT ABDOMINAL PAIN AND ILEOCOLIC INTUSSUSCEPTION IN A 6-YEAR-OLD BOY
}

\author{
M. Panayotova ${ }^{1 *}$, D. Simov ${ }^{2}$, N. Raichkov ${ }^{2}$, M. Georgieva', Zh. Zhelyazkov², K. Kalinova ${ }^{2}$, \\ P. Chakarova ${ }^{1}$ \\ ${ }^{1}$ Department of Pediatrics, Faculty of Medicine, Trakia University, Stara Zagora, Bulgaria \\ ${ }^{2}$ Department of Pediatric surgery, University Hospital "Prof. Stoyan Kirkovich”, Stara Zagora, Bulgaria
}

\begin{abstract}
Burkitt lymphoma is a highly aggressive form of Non - Hodgkin lymphoma that responds favorably to early treatment. The disease has many forms of clinical presentations. It is diagnosed in children usually as an abdominal mass. The tumor causes either indirect symptoms, due to pressure phenomena or direct involvement of the bowel lumen leading to either intestinal obstruction or intussusception.

We report a case of a 6-year-old immunocompetent Caucasian boy who experienced a recurrent abdominal pain (RAP) for the last four months. After symptoms of bowel obstruction, we operated on him at the Department of Pediatric Surgery and ileocolic intussusception was found. We performed right colectomy. Sectioning the invaginate we found a tumor, spreading from the terminal ileum and involving the ileocecal valve. The tumor was immunohistochemically verified as Burkitt lymphoma. CT of neck, mediastinum and abdomen showed polyadenopathy. The child was referred to the pediatric hematology center for chemotherapy.

Conclusion: Burkitt lymphoma rarely causes recurrent abdominal pain in children. The common presentation are bowel obstruction and intussusception. The possibility of lymphoma should be considered in case of intussusception in older children. Therapeutic approach includes combination of surgery and chemotherapy.
\end{abstract}

Key words: recurrent abdominal pain, intussusception, child, Burkitt lymphoma

\section{INTRODUCTION}

Burkitt lymphoma consists $8-10 \%$ of all tumors in children up to 15 years of age $(1,2)$. Nonendemic Burkitt lymphoma is an aggressive and rapidly developing B-cell lymphoma but responds favorably to early treatment (3). Therapeutic approach includes combination of surgery and chemotherapy $(3,4,5)$. The disease usually presents with abdominal localization unlike endemic variant. The latter form is common in Africans, affects the facial bones and is associated with translocation $\mathrm{t}(8 ; 14)$ and Ebstein-Barr virus. The non-endemic forms present with abdominal mass or ascites $(2,6)$.

*Correspondence to: Marlena Panayotova,MD, Trakia University - Stara Zagora, Bulgaria, Medical Faculty, Department of Pediatrics, 11 Armeiska str., Stara Zagora 6000,marlenapanayotova@abv.bg
The common presentation are bowel obstruction and intussusception $(7,8)$. Burkitt lymphoma as a cause of intussusception is rare and presentation with recurrent abdominal pain is even rarer.

\section{CASE REPORT}

A 6-year-old boy presented with history of recurrent abdominal pain in the umbilical region four months ago (R.D.T, hospital record № 18650/2014 year at University Hospital "Prof. Stoyan Kirkovich", Stara Zagora, Bulgaria). There were no signs of toxic infectious syndrome or dyspeptic symptoms at hospital admission; normal bowel movements; no genetic predisposition to gastrointestinal disease. During this period, the boy was hospitalized in several departments (of pediatrics and pediatric surgery), where no changes in his objective status and 
routine hematology tests have been stated. Screening for celiac disease and Helicobacter pylori (H. pylori) infection (stool antigen test) was performed, which turned out negative. In a consecutive pain episode we observed also abdominal swelling with a lack of flatus and defecation. The abdominal X-ray in standing position showed hydroaeric levels and the child was admitted at the Department of Pediatric Surgery, diagnosed with bowel obstruction. Routine hematology and biochemistry tests were normal. Abdominal US of parenchymal organs was unremarkable, only excessive gas collection and a little free liquid in the abdominal cavity. The computer tomography (CT) of the abdomen was normal. Tumor formation in the right upper quadrant was palpated, which required surgical intervention. During the operation we discovered ileocolic intussusception, density of the terminal ileum and ileocecal valve and conglomerate of enlarged lymph nodes in the mesenterium. (Figure 1) Sectioning the invaginate, we found a tumor formation, which was sent for histological examination (Figures 2 and 3). This required right colectomy and lateroterminal ileocolic anastomosis. The conclusion of the immunohistological analysis of the tumor was Burkitt lymphoma. Postoperatively, CT of neck, thorax and abdomen showed cervical, mediastinal and abdominal lymphadenomegaly, hydronephrosis I-II degree on the right kidney (Figures 4 and 5). The child was referred to pediatric hematology center for chemotherapy.

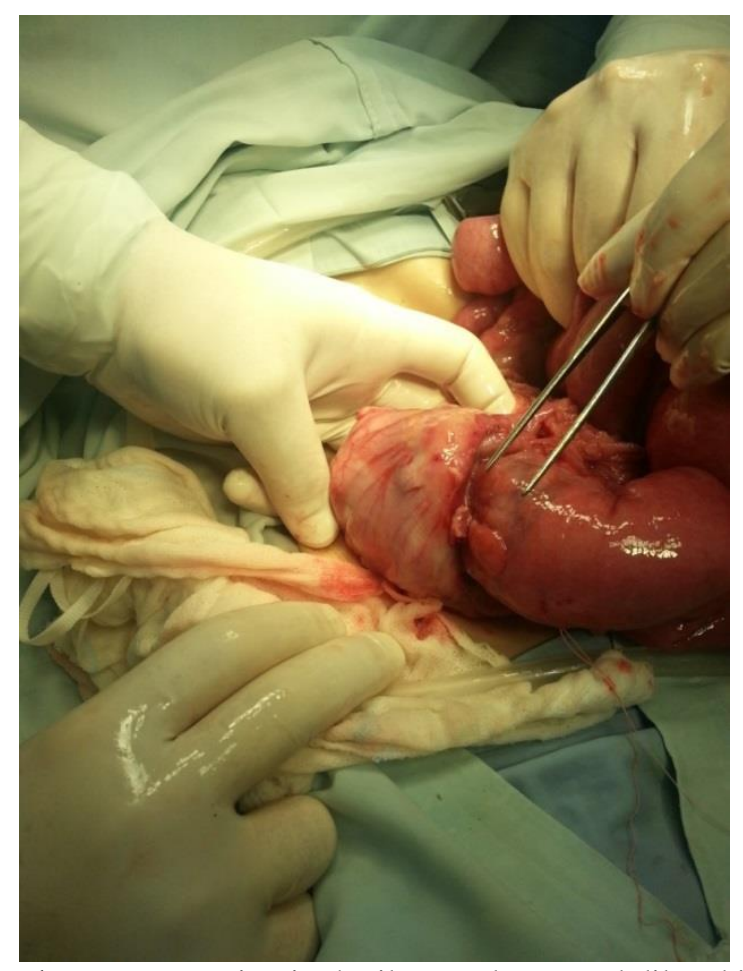

Figure 1. Intussusception in the ileocecal area and dilated ileum.

\section{DISCUSSION}

Non Hodgkin lymphoma (NHL) is the third most common malignant tumor (10\%) and accounts for approximately $60 \%$ of all lymphomas in childhood. The four forms are: Burkitt lymphoma (40\%), lymphoblastic lymphoma (30\%), diffuse large B-cell lymphoma (20\%) and anaplastic large cell lymphoma (10\%) (2). Two clinical subtypes are accepted: endemic and sporadic which have been typical for different regions. Sporadic Burkitt lymphoma affects young children. The most common symptoms are abdominal mass, intestinal obstruction, intussusception and acute abdomen $(4,9)$. The report about presentation of recurrent abdominal pain (RAP) is rare. The boy experienced RAP for four months. He was investigated for celiac disease, H. pylori infection, parasitosis which was not proved. Mesenteric lymphadenitis was reasonable diagnosis at prior consultation for RAP. The case might be of chronic recurrent intussusception. This condition would explain the normal abdominal US before the operation. Finally the bowel obstruction of our patient demanded emergent surgical intervention. Intussusception in older children is always 
secondary $(3,10)$. Predisposing factors for this are polypus, lymphoma, Meckel's diverticulum and Henoch - Schonlein purpura (11). In this case a rare Burkitt lymphoma was proven, involving the terminal ileum and the ileocecal valve, as well as dissemination in adjacent tissues, which is proven by the lymphadenomegaly, found intraoperatively and with CT.

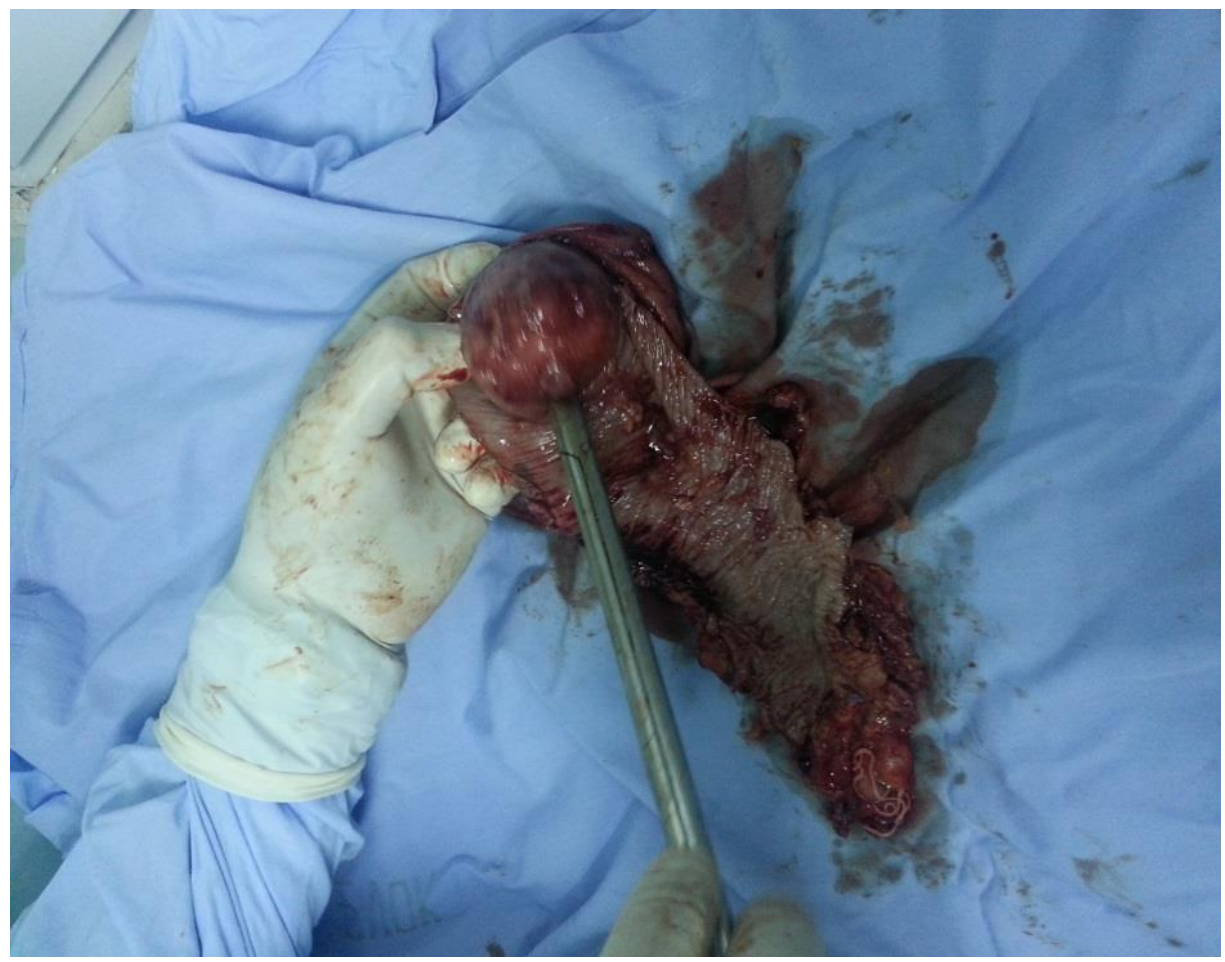

Figure 2. Tumor formation, spreading from the terminal ileum and the ileocecal valve, involved in the intussusception

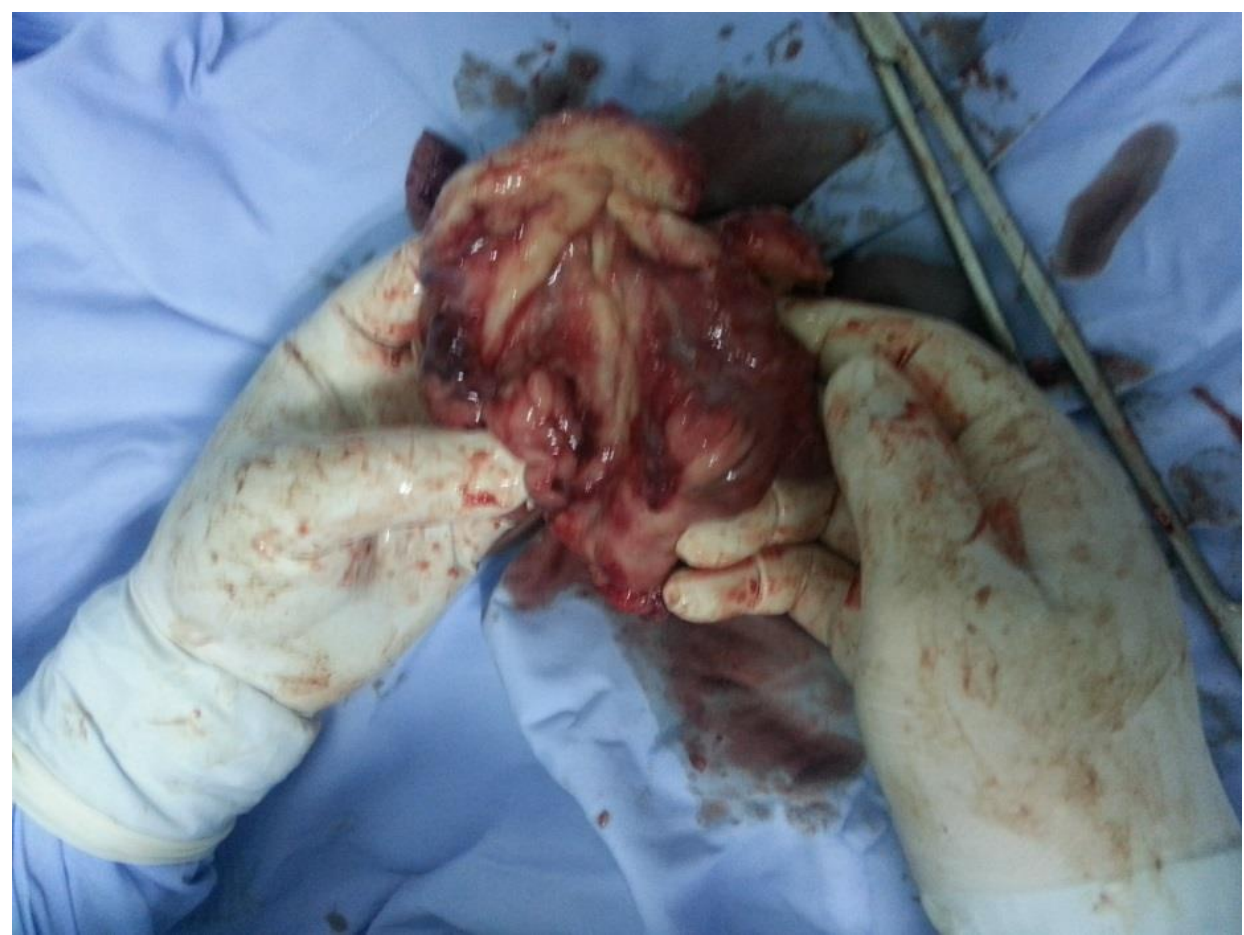

Figure 3. Incision of the tumor formation. 


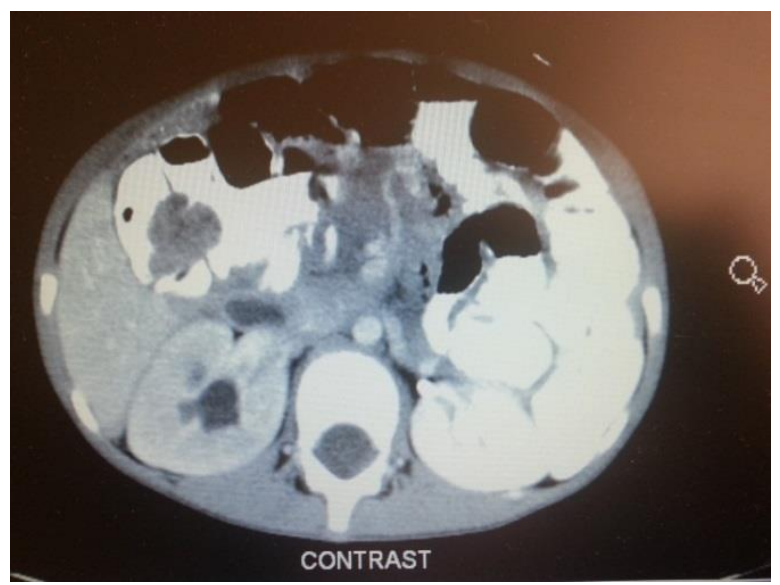

Figure 4. Abdominal CT of the child

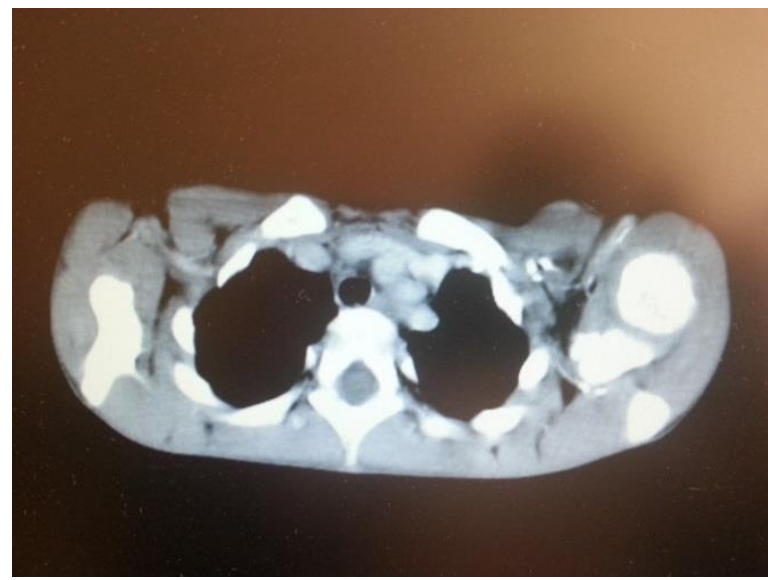

Figure 5. Neck CT of the child

\section{CONCLUSION}

Burkitt lymphoma rarely causes recurrent abdominal pain in children. The common presentation are bowel obstruction and intussusception. The diagnosis can be provided by histopathological and immunohistochemical studies. The possibility of lymphoma should be considered in case of intussusception in older children. Therapeutic approach includes combination of surgery and chemotherapy.
Abbreviations
RAP- recurrent abdominal pain
CT - computer tomography
H. pylori-Helicobacter pylori
US - ultrasound imagine
NHL - Non Hodgkin lymphoma

\section{REFERENCES}

1. Angotti R, Ferrara F. Intussusception in a child with sporadic Burrkitt lymphoma. JSAS, 1:1, 2009.
2. Balanescu NR, Topor L, Malureanu D, Stoica I. Ileocolic intussusception due to Burkitt lymphoma : a case report. $\mathrm{J} \mathrm{Med}$ Life Mar;6(1):61-64, 2013.

3. Grajo JR, Kayton ML, Thora SS, Steffensen TS, Dragijevich N, Guid CB. Presentation of Ileal Burkitt Lymphoma. J Radiol Case Rep. Aug; 6(8):27-38, 2012.

4. Brankov O, Dumanov K, Stoilov S, Doinova P, Drebov R, Khristova I. NonHodgkin's primary lymphoma - a cause of acute abdominal manifestation in children. Khirurgiia (Sofia), (4):10-3, 2007.

5. England RJ, Pillay K, Davidson A, Numanoglu A, Millar AJ. Intussusception as a presenting feature of Burrkitt lymphoma: implications for management and outcome. Pediatr Surg Int, Mar;28(3):267-70, 2012.

6. Abbasoğlu L, Gün F, Salman FT, Celik A, Unüvar A, Görgün $\mathrm{O}$. The role of surgery in intraabdominal Burkitt's lymphoma in children. Eur J Pediatr Surg 2003 Aug;13(4):236-9

7. Alarcón CM, Diaz LM, Valero JS, Cantero $\mathrm{MV}$, Parilla $\mathrm{P}$. Ileocolic invagination in Burkitt lymphoma. Cir Esp Aug;88(2):1245, 2010.

8. Wang SM, Huang FC, Wu CH, Ko SF, Lee SY, Hsiao CC. Ileocecal Burkitt's lymphoma presenting as ileocolic intussusception with appendiceal invagination and acute appendicitis. $J$ Formos med Assos Jun, 109(6):476-9, 2010.

9. Brekalo Z, Kvesić A, Galić G, Kukić-Brusić $\mathrm{S}$, Martinović V, Jonovska S. Burkitt's lymphoma in the boy: infiltration the stomach, colon and the retroperitonerm ileocecal invagination. Coll Antropol. Dec;31(4):1183-6, 2007.

10. Gupta H, Davidoff AM, Pui CH, Shochat SJ, Sandlund JT. Clinical implications and surgical management of intussusception in pediatric patients with Burkitt lymphoma. $J$ Pediatr Surg Jun;42(6):998-1001, 2007.

11. Delarue A, Bergeron C, Mechinaud-Lacroix F, Coze C, Raphael M, Patte C; pour le "Comite Lymphome" de la SFCE. J Chir (Paris). Sep-Oct;145(5):454-8, 2008. 